\title{
A Twenty-Year Follow-Up Case Study of an Office Worker Who Returned to Work despite Serious Memory Disorder Caused by Herpes Encephalitis
}

\author{
Mitsuko Nakano $^{{ }^{*}}$, Nobuo Miyashita ${ }^{2}$, Kazutaka Tanabe ${ }^{3}$, Takeshi Yamamoto ${ }^{4}$ \\ ${ }^{1}$ Department of Neurosurgery, Juntendo University School of Medicine, Tokyo, Japan \\ ${ }^{2}$ Miyashita Neurological Clinic, Nagano, Japan \\ ${ }^{3}$ Department of Neurology, Tokyo Metropolitan Matsuzawa Hospital, Tokyo, Japan \\ ${ }^{4}$ Department of Neurology, Higashi-Matsudo Municipal Hospital, Matsudo City Welfare and Medical Center, Chiba, Japan \\ Email: ${ }^{*}$ m-naka27@jd5.so-net.ne.jp
}

Received July 31, 2012; revised August 24, 2012; accepted September 11, 2012

\begin{abstract}
This study followed a 52-year-old male patient, who had suffered from severe impairment in recent memory due to sequelae of herpes encephalitis, for 20 years. He returned to his highly intellectual work and performed well despite his doctor's prediction. While the patient showed consistently poor results on various neuropsychological memory tests, he demonstrated incredible performance at work. This case exemplifies an extreme case that declarative memory is formed with the support of semantic memory, procedural memory, and his strong interests. Additionally, it offers lessons that results on memory tests do not necessarily correspond to the actual level of competence. The focal sites were found on both sides of the medial temporal lobe, predominantly on the left side. The $\mathrm{T}_{2}$-weighted magnetic resonance images (MRI) obtained 9 years after the onset confirmed widespread damage to the left brain including parahippocampal gyrus, hippocampus, spindle gyrus, and amygdaloid complex, with microlesions extending from the right parahippocampal gyrus to its antero-interior rim. However, the damage to hippocampus was presumed to be minor.
\end{abstract}

Keywords: Declarative Memory; Semantic Memory; Procedural Memory; Hippocampal Damage; Recent Memory; Herpes Encephalitis

\section{Introduction}

Memory consists of declarative memory (episodic memory and semantic memory), procedural memory, and priming memory [1,2]. Previous studies have revealed that injuries to the hippocampus and related structures lead to impairments in recent memory of declarative memory while procedural memory and priming memory are preserved [3-7]. Patient with herpes simplex encephalitis may be left with an isolated, dense amnesic syndrome [5]. We had an opportunity to study over 20 years the case of a patient who had suffered from serious damage to the bilateral hippocampus region predominantly on the left side as sequelae of herpes encephalitis.

Herpes simplex encephalitis (HSE) is a rare, but severe viral infection of the human central nervous system. Most patients with HSE show a decrease in the level of consciousness and an altered mental state presenting as confusion, and changes in personality. Patients typically have a fever and may have seizures. The electrical activity of the brain changes as the disease progresses, first

\footnotetext{
"Corresponding author.
}

showing abnormalities in one temporal lobe of the brain, which spread to the other temporal lobe later. The most common long term symptoms were memory impairment (69\%), personality and behaivioral abnormalities (45\%), and epilepsy (24\%) [8,9].

The patient we are reporting in this study had succeeded in resuming his highly intellectual work at an excellent level while he had been consistently demonstrating poor results on neuropsychological tests of memory that we had administered for over 14 years since the onset. Generally, results from neuropsychological tests correspond well with actual levels of social abilities, and thus it is significant to make such assessments. However, the patient's performance on the tests and vocational abilities had remarkable discrepancies in this case.

The patient's memory disabilities had become noticeable in the first three years. He could not achieve computer skills all through his life, but his knowledge and ability to think and decide, which were all required for his work, were significantly well retained, and thus he successfully returned to work. He could work in the same way as before the onset and was even promoted. More- 
over, his performance during activities in which he has strong interests, such as crossword puzzles and Sudoku (number puzzle), improved substantially and he was even able to win the prizes.

His memory, which had effective support by his knowledge and interests, had been well retained, and his learning effects had also increased, while simple memories without such supports were poor and did not return.

This case reveals an exceptionally unique example in which memory is not only a hippocampal function, but is also significantly supported by accumulated knowledge and interests.

\section{Case}

The patient is a right-handed 73-year-old male, a company employee (accounting). In October 1987, he suffered from a high fever around 38 - 39 degrees Celsius at the age of 52, and it lasted several days. As a conesquence, severe impairment in recent memory and disorientation occurred. He was diagnosed with herpes encephalitis after examination of the cerebrospinal fluid, and had treatment after admission to the Department of Neurology, Juntendo University Hospital in Tokyo. One month after the onset of fever, his disturbed consciousness improved, but serious impairment of recent memory continued. For several months, the patient could not remember taking a meal immediately before, nor whether his wife has visited him only ten minutes ago. During the 3-month period of hospitalization, the patient kept asking questions such as "Why am I staying here?" and "What shall I do from now on?" He was able to recognize his doctor's face, but failed to remember his name. Nevertheless, he surprised his neurologist by reporting that he had completed an income tax return form at the request of his acquaintance during his brief, temporary discharge from the hospital three months after the onset of the memory disorder.

We had sessions every week with the patient during and after his hospitalization for three months prior to his return-to-work training to improve his memory. We had given him homework with the support of his wife; however, his memory disorder showed no recovery at this point.

Despite the neurologist's diagnosis that he had no potential for professional comeback, he successfully returned to work in his previous business firm. Initially, he did not understand his way to his office, so his subordinate showed his way by car several times. Later on, the patient went to work by himself using a car navigation system. At first, the company had given him jobs that were not related to his original accounting responsibilities and that did not require the use of memory, such as "copying family trees," which was apparently prepared especially for him. Shortly thereafter, colleagues found that his abilities to accomplish his original jobs such as checking accounting materials had not declined, and thus he returned to his previous post. Three months after his return, he received a bonus, and furthermore, he received more salary and bonus than his colleagues in the following year.

The patient's colleagues and subordinates were aware of his memory impairment. His boss reported that when his boss asked the patient's colleague about whether he was competent, his colleague replied that he might have been a little less competent than before, but his retained capacity was good enough as his ability was very outstanding to begin with. According to his wife, memory impairment often occurred during the first three years after the onset. For example, he did not remember about a package which he received and placed at the entrance by himself, and asked his wife what the strange object was five minutes later.

At work, he was appointed as a board member at the ge of 56, which is four years after the onset, and retired at 60 after he had been allowed to postpone retirement twice. A small company run by his brother-in-law rehired him as an accounting manager, and he finally retired at 65.

He had never visited his doctor for follow-ups after being discharged because he maintained a good physical condition, as well as he was occupied with his work. Therefore, we told him to visit the hospital whenever he had time. We had administered memory and medical tests three times by the time he turned 60 and 12 times after age 60 . Those results consistently and continually illustrated that his work performance was inevitably incredible (Tables 1-4). The MRI results showed no improvement as well (Figure 2).

One of his hobbies was reading mystery novels before the onset; however, he could not remember the story after being ill and thus began crossword puzzles instead. He remembered the monthly publication dates of 18 different crossword puzzle magazines. For several years, he was absorbed in solving crossword puzzles and won many prizes. He now enjoys Sudoku, which is numberplacement puzzles, every morning. Additionally, he plays Shogi, which is a traditional Japanese game resembling chess requiring prominent recent memory, every week with his Shogi friends. He reached the level of 2nd Dan (grade) given to advanced players.

\section{Examinations}

\subsection{Medical Examination}

\subsection{1. $T_{2}$ Weighted Magnetic Resonance Image, MRI} $\left(T_{2}\right)$

At a year and two months after the onset of herpes en- 
cephalitis, damage to the bilateral hippocampus was confirmed by weighted MRI $\left(\mathrm{T}_{2}\right)$.

High-intensity areas were observed over a wide basilar to anterior area including the hippocampus on the left side as well as to one-third of the medial region on the right side of the anterior temporal lobe (Figure 1). At eight years and seven months after the onset of herpes encephalitis, damage was still recognized over a wide range on the left side, including the parahippocampal gyrus, the hippocampus, the spindle gyrus, and the amygdaloid complex. On the right side, smaller lesions were present in the parahippocampal gyrus extending to the antero-interior rim, but the damage to the right hippocampus was assumed to be slight (Figure 2).

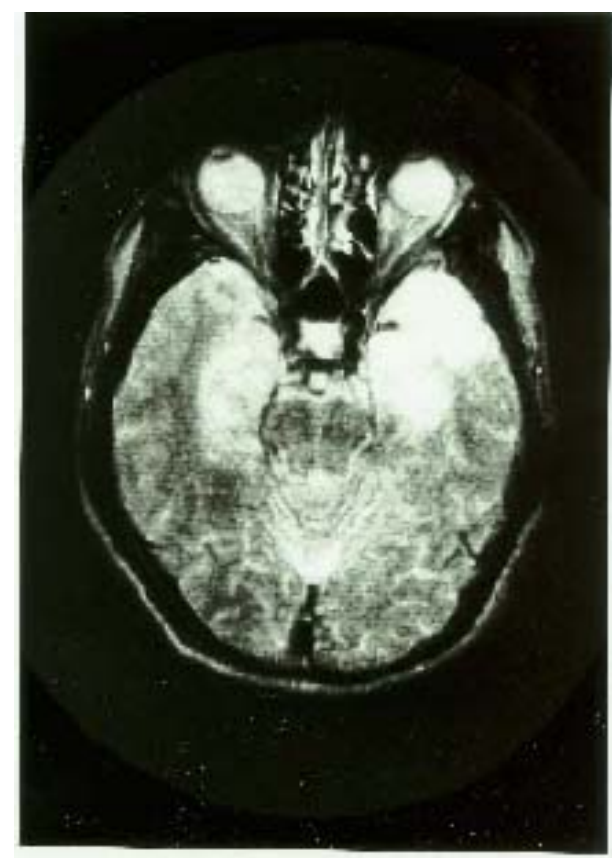

Figure 1. Axial MRI $\left(T_{1}\right)$ at 1 year and 6 months after the onset of herpes encephalitis.

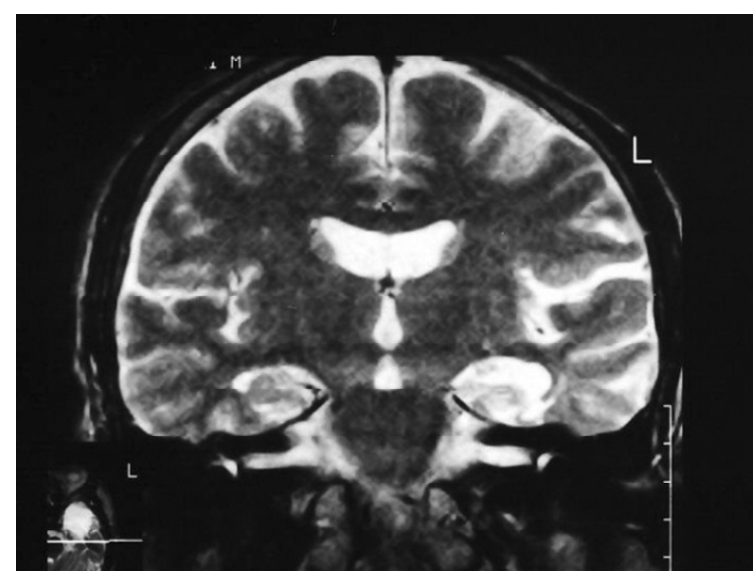

Figure 2. Coronal MRI $\left(\mathrm{T}_{2}\right)$ at 8 years and 7 months after the onset of herpes encephalitis.

\subsubsection{Cerebral SPECT Using 1231 IMP}

Single-photon emission computed tomography (SPECT) performed at eight years and eleven months after the onset demonstrated a decreased cerebral perfusion at the tips of the bilateral temporal lobes predominantly on the left side.

\subsubsection{Electroencephalography}

At eight years and six months after the onset of herpes encephalitis, slow waves were predominant in the background waves. Especially, during the shallow first-stage sleep, slow waves in the temporal region were obviously abnormal.

\subsection{Psychological and Neuropsychological Assessmentt}

\subsubsection{Wechsler Adult Intelligence Scale (WAIS)}

Wechsle Intelligence Scale for Adult (WAIS) in Japanese

Table 1. <Results of Wechsler Adult Intelligence Scale (WAIS)>

\begin{tabular}{|c|c|c|c|c|}
\hline \multicolumn{5}{|c|}{ Time after encephalitis onset } \\
\hline & 26 days & 2 months & 3 months & $\begin{array}{c}8 \text { years } 7 \\
\text { months }\end{array}$ \\
\hline VIQ & 107 & $\begin{array}{c}\text { not } \\
\text { performed }\end{array}$ & 108 & 119 \\
\hline PIQ & $\begin{array}{c}\text { not } \\
\text { performed }\end{array}$ & 109 & $\begin{array}{c}\text { not } \\
\text { performed }\end{array}$ & 130 \\
\hline FIQ & & & & 124 \\
\hline Information & 11 & & 10 & 14 \\
\hline Comprehension & 12 & & 11 & 12 \\
\hline Arithmetic & 10 & & 11 & 9 \\
\hline Similarities & 7 & & 7 & 10 \\
\hline Digit span & 10 & & 13 & 10 \\
\hline Vocabulary & 15 & & 14 & 17 \\
\hline Digit symbol & & 13 & & 17 \\
\hline Completion & & 8 & & 11 \\
\hline Block design & & 13 & & 12 \\
\hline $\begin{array}{c}\text { Picture } \\
\text { arrangement }\end{array}$ & & 11 & & 10 \\
\hline $\begin{array}{c}\text { Objects } \\
\text { assembly }\end{array}$ & & 7 & & 10 \\
\hline
\end{tabular}

The average of WAIS subtests $(0$ - 19) is 10 .

$<$ Wechsler Memory Scale-Revised $>$

\begin{tabular}{cccc}
\hline \multicolumn{4}{c}{12 years 4 months after encephalitis onset } \\
\hline Verbal memory & Visual & General & Delayed \\
& memory & memory & memory \\
53 & 70 & 59 & $<50$ \\
\hline
\end{tabular}

Note: The WAIS and WMS-R indices yield a mean score of 100 in the normal population with a standard deviation of 15 . The average of the results of WAIS subtests $(0-19)$ is 10 . In normal subjects, the WMS-R is equivalent to the WAIS. The span of delayed memory (55 yrs - 64 yrs) is 109 0.0 is correspondence to IQ $<50$. 
edition is consisting of 6 verbal subtests (verbal IQ,VIQ) and 5 nonverbal subtests (performance IQ, PIQ). The WIAS indicates yeald a mean score of 100 in the normal population with a standard deviation of 15 . The span of each IQ is from 60 to 140 . The average of each subtest (on each scale from 0 to 19) in the WAIS is 10.

The patient's verbal IQ remained at an average level based on the test administered one month after the onset, and his Performance IQ remained at average as well on the test administered another month later. Administration of the same test eight years and seven months after the onset revealed that his Performance IQ was 130, which demonstrated a remarkable improvement compared to the increase in his Verbal IQ. This indicated that the patient was highly intelligent by nature.

\subsubsection{Wechsler Memory Scale Revised (WMS-R) [10]}

This test was designed to assess auditory and visual delayed memory and auditory and visual immediate memory abilities in adults and adolescents.

The span of the index scores of WMS-R yields from less than 50 to 140 which is correspond to the IQ of WAIS in normal population.

The WMS-R was administered 12 years and four months after the onset of the disease. Both his verbal memory and visual memory had deteriorated, and the delayed memory showed a raw score of 0 which indicated he could memorize nothing.

\subsubsection{Sentence Compliment Test (SCT) [11]}

The SCT was administered two months after the onset of the disease. This test provides respondents with several prompt words to begin the sentence, and respondents are required to complete them in anyway. There are 60 of them in the test. The result indicated clear sentence structures as well as logical and meaningful contents, and proved that his thinking ability was intact. Use of Kanji (Chinese characters) was also appropriate and correct.

Neuropsychological Assessment.

\subsubsection{Edinburgh Handedness Inventory [12]}

It was administered in December, 2002, and the result was LQ 100 and right handed.

\subsubsection{Wisconsin Card Sorting Test (WCST, R-Milner Method) [11]}

The WCST is a card sorting test which examines the ability to form abstract concepts , abstract thinking, and flexibility of thinking. The normal range is Categories Achieved (CA) $>5 / 6$, Perseveration Errors $(P)<5$. The WCST was administered twice. We administered it for the first time in July 1989, which was two years and 10 months after the onset of the disease. The result was 6/6(CA), 3(P), and 3 (True Errors: TE), which revealed few errors .We administered it a second time on November 1st, 1996, 11 years after the onset. The result was 5/6(CA), 1(P), and 1 (Other Error: OE). Two total errors indicated that the patient's concept formation and flexibility of thinking was well maintained, and he was capable of abstract thinking as well as flexible adaptation to the surrounding environment.

$<$ Verabal Memory Tests $>$

\subsubsection{Suzuki Binet Intelligence Test, No. 43 (Auditory Verbal Memory of Contents of Sentence) [11] (Table 2)}

The tester reads out the sentence (15 words). Immediately after that the subject recall the contents of the sentence as many as possible he can.

\subsubsection{Verbal Paired Associate Tests, Tokyo University Method [11] (Table 2)}

The tester read out loud a list of words with a relative pair (i.e., sky and starts) first. The tester then read the first pair of words, and the subject answered the matching word of the pair. This process is repeated three times to examine the learning effects.

The accuracy rate for healthy subjects is $85 \%$ for the first trial, $98 \%$ for the second trial, and $100 \%$ in the third trial (Therze are no mentions of the age on this test).

The list of words with an unrelated pair was too difficult to administer in this case. The patient's results displayed neither improvement nor learning effect by repetition.

\subsubsection{Rey’s Auditory Verbal Learning Test (AVLT) [10]}

This test measures immediate memory span, provides a learning curve, reveals learning strategies. The test consists of 15 nouns (List A) that are read out for five cconsective trials $\left(T_{1}-T_{5}\right)$, each trial followed by a free-recall test. On completion of Trial 5, an interference list of 15 words (List B) is presented, followed by a free-recall test of that list. Immediately after this, delayed recall of the first list is tested (Trial 6, $\mathrm{T}_{6}$ ) without further presentation of those words. Finally, the 30 words including all the List A is presented in written form, and a testee must identify words regnized from List A.

This test has gained popularity in Japan in 2000. We did not recognize neither an improvement nor learning effect from the two administrations (Table 2).

$<$ Visual Memory Tests $>$

\subsubsection{Benton Visual Retention Test (Type I, Trial Method A) [10] (Table 3)}

This test consists of ten cards on which three geometric figures are drawn.The purpose of the test is to assess visual memory, visual perception, and visual-construc- 
tive abilities. It was administered five times.

\subsubsection{Rey-Ostereith Complex Figure [10] (Table 3)}

The purpose of this test is to assess visual-spatial constructional ability and visual memory. The test is consisted of a copy trial followed by a recall trial 15 minites later. We administerd the test following this method. The results demonstrated not only poor but also total failure in recent memory.

Table 2. Results of verbal memory test. <Suzuki Binet Intelligence Scale, 43: Memory of contents of sentence>, time after encephalitis onset: Correct scores

immediate memory

\begin{tabular}{llcccc}
\hline 1 mos & 3 mos & $\begin{array}{c}1 \text { yr } 10 \\
\text { mos }\end{array}$ & 2 yrs 10 mos 8 yrs 7 mos & $\begin{array}{c}15 \text { yrs } 3 \\
\text { mos }\end{array}$ \\
\hline $5 / 15$ & $4 / 15$ & $5 / 15$ & $7 / 15$ & $5 / 15$ & $5 / 15$ \\
\hline
\end{tabular}

3-minute delay

\begin{tabular}{|cccccc|}
\hline 1 mos & 3 mos & $\begin{array}{c}1 \text { yr 10 } \\
\text { mos }\end{array}$ & $\begin{array}{c}2 \text { yrs } 10 \\
\text { mos }\end{array}$ & $\begin{array}{c}8 \text { yrs } 7 \\
\text { mos }\end{array}$ & 15 yrs 3 mos \\
\hline $0 / 15$ & $0 / 15$ & $0 / 15$ & $0 / 15$ & $0 / 15$ & $0 / 15$ \\
\hline
\end{tabular}

The accurate rate of immediate recall was 8 out of 15 , and it corresponds to the MA of 10-year old.

<the Verbal Paired Associates Test, Tokyo University Method>, Time after encephalitis onset: Correct scores for 10 meaningful associates

\begin{tabular}{ccccccc}
\hline $\begin{array}{c}\text { No.of } \\
\text { trial }\end{array}$ & $\begin{array}{c}3 \\
\text { wks }\end{array}$ & 2 mos & 4 mos & $\begin{array}{c}5 \text { yrs } 4 \\
\text { mos }\end{array}$ & $\begin{array}{c}8 \text { yrs } 7 \\
\text { mos }\end{array}$ & $\begin{array}{c}15 \text { yrs } \\
3 \text { mos }\end{array}$ \\
\hline 1st & 0 & 1 & 3 & 1 & 4 & 1 \\
2nd & 0 & 2 & 5 & 2 & 4 & 2 \\
3rd & 0 & 3 & 4 & 4 & 5 & 4 \\
4th & & 3 & 7 & & & \\
5th & & 5 & 5 & & & \\
6th & 2 & & & & \\
7th & 5 & 4 & & & & \\
8th & & 4 & & & & \\
9th & & & & & & \\
10th & & & & & & \\
\hline
\end{tabular}

Although the accurate rate of healthy subjects is written $85 \%$ for first trial, $98 \%$ for second trial, $100 \%$ in third trial, no description about age were written in the manual.

$<$ Rey's Auditory Verbal Learning Test (RVALT)>, Time after encephalitis onset: Correct scores for 15 words $\left(T_{1}-T_{6}, B\right)$

\begin{tabular}{ccccccccc}
\hline & $\mathrm{T}_{1}$ & $\mathrm{~T}_{2}$ & $\mathrm{~T}_{3}$ & $\mathrm{~T}_{4}$ & $\mathrm{~T}_{5}$ & Total & $\mathrm{B}$ & $\mathrm{T}_{6}$ \\
\hline 12 yrs 4 mos & 5 & 5 & 4 & 3 & 5 & 22 & 2 & 5 \\
15 yrs 3 mos & 3 & 5 & 4 & 5 & 5 & 22 & 0 & 3 \\
\hline
\end{tabular}

The normative score $(60-69 \mathrm{yr})$ of the total is $36.7 \pm 8.4$, and $\mathrm{T}_{6}$ (Retention) is $7.0 \pm 2.9$.
Table 3. The results of visual memory

$<$ Benton Visual Retention Test $>$

\begin{tabular}{cc}
\hline Time after encephalitis onset & Correct scores \\
\hline 1 month & $4 / 10$ \\
3 yrs 1 mos & $4 / 10$ \\
8 yrs 7 mos & $4 / 10$ \\
9 yrs 0 mos & $6 / 10$ \\
10 yrs 1 mos & $7 / 10$ \\
\hline
\end{tabular}

Normative data for ages 60 - 69 yrs (Education 18 yrs) of immediate recallis $6.80 \pm 1.55$.

$<$ Rey-Osterrieth Complex Figures $>$

\begin{tabular}{ccc}
\hline & \multicolumn{2}{c}{ Correct scores } \\
\hline $\begin{array}{c}\text { Time after encephalitis } \\
\text { onset }\end{array}$ & Immediate recall & Delayed recall \\
9 yrs 3 mos & $4 / 36$ & $0 / 36$ \\
10 yrs 1 mos & $5 / 36$ & $0 / 36$ \\
15 yrs 4 mos & $5 / 36$ & $0 / 36$ \\
\hline
\end{tabular}

Normative data for ages $60-69$ yrs of 30 -min delayed recall is $14.21 \pm 7.50$.

Table 4. < Immediate auditory and visual memory of digit span>, correct scores for 10 kinds of digit span consisting of 4 to 9 digits

\begin{tabular}{ccccc}
\hline & \multicolumn{4}{c}{ Times after encephalitis onset } \\
\cline { 2 - 5 } Presentation & $\begin{array}{c}\text { Auditory } \\
\text { pre }\end{array}$ & $\begin{array}{c}\text { Visual } \\
\text { pre }\end{array}$ & $\begin{array}{c}\text { Auditory } \\
\text { Pre }\end{array}$ & $\begin{array}{c}\text { Visual } \\
\text { pre }\end{array}$ \\
Digit span & & & & \\
4 & 10 & 10 & 10 & 10 \\
5 & 5 & 10 & 8 & 10 \\
6 & 2 & 10 & 8 & 10 \\
7 & 2 & 8 & 5 & 8 \\
8 & 2 & 7 & 4 & 10 \\
9 & 1 & 1 & 1 & 3 \\
\hline
\end{tabular}

\subsubsection{Comparison between Auditory and Visually Memory Test on Digit Span}

This test consists of ten items of digit span in each digit number. The tester read out loud each number every two seconds in the auditory version, whereas the tester displayed each card with an item every four seconds in the visual version. The patient performed well on visual memory, but poor on the auditory version.

\section{Discussion}

This is a significant case that validates several essential hypotheses which has been long proposed regarding mem- 
ory. Additionally, this didactic case demonstrates that results on memory tests do not necessary correspond to actual capabilities.

The fact that the patient's semantic memory related to his job and proceeding memory to perform paperwork were maintained right after the recovery from the disturbance of consciousness was obvious by his success in completing tax return documents after temporary discharge from the hospital. Moreover, the results on WAIS, SCT, and Wisconsin Card Sorting Test results, and the evidence by his colleagues revealed that his intellectual ability, except for memory, was very well retained. Luck was indeed involved in him getting the opportunity to return to work; because he was in a position to supervise his staff, and his job was to check the accountant paperwork which his subordinates created, he only needed to confirm if the paperwork was correct by corresponding the information with his knowledge. It would have been impossible to perform if his job included learning how to use a computer. He was able to keep working and was even promoted only because he conserved work-related knowledge and remembered how to complete the paperwork, and his work skill was retained. Additionally, he has been superior in terms of his hobby such as puzzles and Shogi.

Many researchers claimed that priming effects on declarative memory and amnesia is more affected than Korsakov's syndrome $[13,14]$ and this case of amnesia totally supports their hypothesis. Hamann and Squire (1997) [2] claimed that separating priming memory from declarative memory is difficult; however, if a clear distinction exists between recent memory that is supported by priming memory and the one that is not, as this case revealed, it indirectly portrays that the priming memory is actually functioning.

We assume from its course that the patient's recent memory had quickly rcovered on his job as Brandt, Gardiner, Vargha-Khadem, Baddeley, \& Mishkin (2006) [15] claimed that semantic memory could boost episodic recall.

Additionally, remote memory was retained even though recent memory was affected. This supports the claims by Squire and Zola-Morgan (1991) [16] that "as time passes after learning, memory stored in the neocortex gradually becomes independent of the medial temporal lobe structure”. Kapur and Brook (1999) [17] also supported this theory.

However, at the same time he was succeeding in his work and winning a prize for crossword puzzles, he performed very poorly on neuropsychological examinations regarding his memory. The reason for this result was assumed that unlike his job and hobbies, he retained no knowledge related to the items he needed to remember in the psychological/neuropsychological test, and he had no interests toward them, and thus the damage to the hippocampus directly appeared.

He successfully remembered during his work because his memory related to work was supported by his knowledge and interests, while he could well perform on his hobbies such as crossword puzzles, Sudoku, and Shogi because they are enjoyable for him and his priming memory was functioning. It is assumed that the right hippocampus possibly compensates for the functional damage to the left hippocampus with supports of his own intellectuality, strong motivation, and interest. The damage to his memory thus recovered to a certain level in selective situations despite the fact that the left hemisphere damage was wide spread and severe.

\section{REFERENCES}

[1] E. Tulving and D. L. Schacter, "Priming and Human Memory Systems,” Science, Vol. 247, No. 4940, 1990, pp. 301-306. doi:10.1126/science.2296719

[2] S. B. Hamann and L. R. Squire, "Intact Perceptual Memory in the Absence of Conscious Memory," Behavioral Neuroscience, Vol. 111, No. 4, 1977, pp. 850-854. doi:10.1037/0735-7044.111.4.850

[3] S. Corkin, "AcquisitionL of Motor Skill after Bilateral Medial Temporal-Lobe Excision,” Neuropsychologia, Vol. 6, No. 3, 1968, pp. 255-265. doi:10.1016/0028-3932(68)90024-9

[4] B. Milner, S. Corkin and M. L. Teuber, "Further Analysis of the Hippocampal Amnesic Syndrome: Fourteen-Year Follow-Up Study of H.M.," Neuropsychologia, Vol. 6, No. 3, 1968, pp.215-234. doi:10.1016/0028-3932(68)90021-3

[5] N. Kapur, "Selective Sparing of Memory Functioning in a Patient with Amnesia Following Herpes Encephalitis," Brain and Cognition, Vol. 8, No. 1, 1988, pp. 77-90. doi:10.1016/0278-2626(88)90040-1

[6] L. R. Squire, J. G. Ojemann, F. M. Miezin, S. E. Pwetersen, T. O. Videen and M. E. Raichle, "Activation of the Hippocampus in Normal Humans: A Functional Anatomical Study of Memory," Proceedings of the National Academy of Science of the United States of America, Vol. 89, No. 5, 1992, pp. 1837-1841. doi:10.1073/pnas.89.5.1837

[7] D. L. Schacter, N. M. Alpert, C. R. Savage, S. L. Rauch, and M. S. Albert, "Conscious Recollection and the Human hippocampal Formation: Evidence from Positron Emission Tomography," Proceedings of the National Academy of Science of the United States of America, Vol. 93, No. 1, 1996, pp. 321-325.

doi:10.1073/pnas.93.1.321

[8] L. Kapur, S. Barker, E. H. Burrows, D. Ellison, J. Brice, L. S. Illis, K. Scholey, C. Corbourn, B. Wilson and M. Loates, "Herpes Simplex Encephalitis: Long Term Magnetic Resonance Imaging and Neuropsychological Proile,” Journal of Neurology, Neurosurgery, and Psychiatry, Vol. 57, No. 11, 1994, pp. 1334-1342. doi:10.1136/jnnp.57.11.1334

[9] N. MacGrath, N. E. Anderson, M. C. Croxson and K. F. 
Powell, "Herpes Simplex Encephalitis Treated with Acyclovir: Diagnosis and Long Term Outcome," Journal of Neurology, Neurosurgery \& Psychiatry, Vol. 63, No. 3, 1997, pp. 321-326. doi:10.1136/jnnp.63.3.321

[10] E. M. S. Strauss, O. Sherman and O. Spreen, "A Compendium of Neuropsychological Test,” 3rd Edition, Oxford, New York, 2006.

[11] M. Nakano, "Clinical Assessment of Intelligence (in Japanese)," Sanno Press, Tokyo, 1996.

[12] M. D. Lezak, “Neuropsychological Assessment,” 3rd Edition, Oxford University Press, New York, 1995.

[13] L. S. Cermak, S. P. Blackford, M. O’Connor and R. P. Bleich, "The Implicit Memory Ability of a Patient with Amnesia Due to Encephalitis,” Brain and Cognition, Vol. 7, No. 2, 1988, pp. 145-156. doi:10.1016/0278-2626(88)90026-7

[14] L. R. Squire and R. D. Mckee, "Declarativeand Nondeclarativememory in Opposition: When Priorevents Influ- ence Amnesic Patients More than Normal Subjects,” Memory \& Cognition, Vol. 21. No. 4, 1993, pp. 424-430. doi:10.3758/BF03197173

[15] K. R. Brandt, J. M. Gardiner, F. Vargha-Khadem, A. D. Baddeley and M. Mishkin, "Using Semantic Memory to Boost 'Episodic' Recall in a Case of Developmental Amnesia,” Neuroreport, Vol. 17, No. 10, 2006, pp. 1057-1060. doi:10.1097/01.wnr.0000220134.09221.04

[16] L. R. Squire and S. Zola-Morgan, “The Medial Temporal Lobe Memory System,” Science, Vol. 253, No. 20, 1991, pp. 1380-1385. doi:10.1126/science.1896849

[17] N. Kapur and D. J. Brooks, "Temporally-Specific Retrograde Amnesia in Two Cases of Discrete Bilateral Hippocampal Pathology,” Hippocampus, Vol. 9, No. 3, 1999 , pp. 247-254.

doi:10.1002/(SICI)1098-1063(1999)9:3<247::AID-HIPO 5>3.0.CO;2-W 